\title{
Thoracoscopy in the treatment of persistent arterial ductus arteriosus in neonates
}

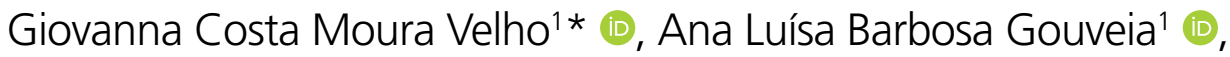 \\ Arthur Bispo de Almeida Pinto' (1), João Guilherme Marques Castello Branco Levy (1), \\ Mayara Maranhão Jorge ${ }^{1}$ (D) Alberto Vilar Trindade ${ }^{1}$ (D), Antônio Claudio Dias Amaral²
}

\section{INTRODUCTION}

Patent ductus arteriosus (PDA) is a congenital deformity. The ductus arteriosus is essential for neonatal circulation, and normally after 2-3 days of life in terms of newborns, it closes. When occlusion does not occur, there is an increase in pulmonary flow associated with systemic hypoperfusion. The major risk factor for PDA is preterm birth and delayed canal closure, which is inversely proportional to gestational age (GA). An estimated $80 \%$ of infants with a GA between 25 and 28 weeks will present with PDA ${ }^{1}$.

In 1977, indomethacin, a prostaglandin synthesis inhibitor agent, became the clinical therapy for ductus arteriosus closure in premature infants. However, in situations in which PDA is refractory to clinical management or when the side effects of clinical treatment outweigh the benefits, its surgical ligation is indicated ${ }^{1}$.

Although open thoracic surgery is common for PDA ligation or clipping, thoracoscopic PDA closure is an alternative surgical procedure that requires a smaller incision, facilitates postoperative recovery, reduces pain, results in shorter hospital stay, and improves respiratory function. There is also a decrease in the incidence of chest wall deformity in the long term, including scoliosis and breast deformity, leading to better aesthetic results ${ }^{2,3}$.

Minimally invasive surgery is increasingly performed in pediatrics, but the physiological characteristics of neonates are associated with a higher risk of intraoperative complications ${ }^{4}$.

Collectively, the studies that make up the current literature on the subject are from centers with extensive experience in minimally invasive surgery, as such, there is still a need for more series of reports comparing thoracoscopy with standard thoracotomy in terms of efficacy, morbidity, and conversion rates, especially in neonates and premature babies ${ }^{3,5}$. Therefore, the objective of this study is to compare thoracoscopy with thoracotomy in the treatment of PDA in neonates.

\section{METHODS}

This study aimed to conduct a narrative review of the literature via an electronic search of the following databases: MEDLINE, SciELO, LILACS, and ScienceDirect. The articles were selected according to the search for the following DeCS descriptors: "Cardiac Surgical Procedures," "Congenital, Hereditary, and Neonatal Diseases and Abnormalities," "Ductus Arteriosus Patent," "Thoracoscopy," and "Minimally Invasive Surgical Procedures."

For the inclusion of articles, we selected mainly those published from 2015 to November 2020, without criteria for the language of origin. Personal communications, conference proceedings, case reports, and duplicates were excluded.

For better organization and applicability of this study, the Population, Intervention, Comparison, and Outcome (PICO) method was used. (P) Study population: full-term or premature neonate patients who submitted to thoracoscopy for the treatment of PDA; (I) intervention: thoracoscopy; $(C)$ comparison: results of thoracoscopy with those of thoracotomy to treat PDA; $(O)$ outcome: thoracoscopy is the procedure of choice for the treatment of PDA due to a decreased incidence of chest wall deformity, shorter hospital stay, and faster postoperative recovery.

${ }^{1}$ Centro Universitário de Brasília - Brasília (DF), Brazil.

${ }^{2}$ Hospital de Base do Distrito Federal, Thoracic Surgery Unit - Brasília (DF), Brazil.

*Corresponding author: giovanna.mouravelho@gmail.com

Conflicts of interest: the authors declare there are no conflicts of interest. Funding: none.

Received on June 15, 2021. Accepted on June 27, 2021. 


\section{RESULTS}

In the first stage, we actively searched for articles using descriptors and specific keywords. Thus, 109 articles were recognized, of which 32 were chosen according to their relevance based on the titles and abstracts. Subsequently, two duplicates were excluded. Table 1 summarizes the information from the most relevant articles: authors, year of publication, title, duration of the study, type of study, study description, patient group, study results, and limitations.

\section{DISCUSSION}

The arterial duct $(\mathrm{AD})$ is an essential vascular conduit for fetal circulation because it enables communication between the systemic and the pulmonary circulation. The $\mathrm{AD}$ anatomically connects the left pulmonary artery to the descending aorta, allowing the passage of more oxygenated blood into the fetal systemic circulation ${ }^{6}$.

After 24-48 $\mathrm{h}$ from birth, the AD undergoes physiological obliteration to ensure the functioning of the pulmonary circulation. However, the persistence of this communication may occur in the neonatal circulation ${ }^{5,7}$. If PDA is not treated, it can result in heart failure, endocarditis, ventricular hypertrophy, and systemic hypoperfusion ${ }^{1,8}$.

\section{Pathophysiology of PDA}

When the AD fails to close, blood flow is maintained through it. However, the flow is reversed due to pulmonary and systemic pressure changes that occur after birth, as demonstrated in Figure $1^{1}$.

The expansion of the lung abruptly decreases the pulmonary pressure and the loss of the placental circulation, which is of low pressure, and results in increased systemic pressure. Thus, the flow within the $\mathrm{AD}$ is reversed, with blood exiting the aorta and proceeding to the pulmonary artery ${ }^{1}$. This reversal causes an increase in the pulmonary circulation and associated systemic hypoperfusion, as the already oxygenated blood returns to the lung ${ }^{1}$.

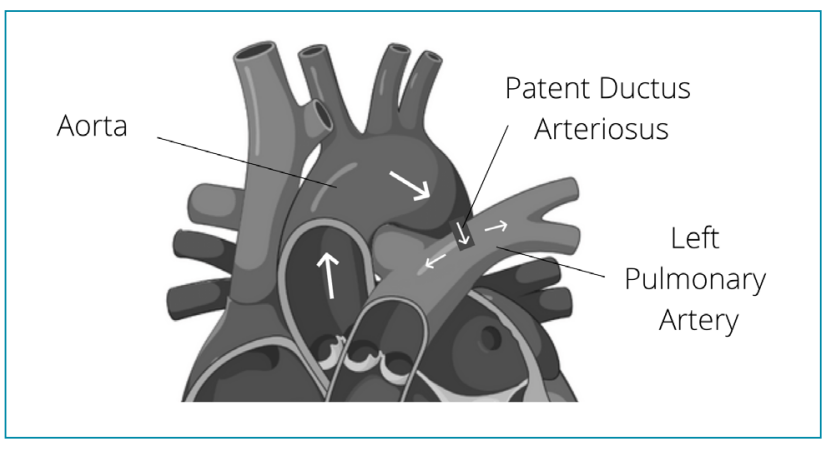

Figure 1. Blood flow with patent ductus arteriosus.
The PDA is related to three factors, namely, prostaglandins (PGs), $\mathrm{O}_{2}$, and nitric oxide (NO). PGs are essential to maintain the patent ductus. In patients with PDA, the AD endothelium has a higher level of $\mathrm{PG}$ receptors ${ }^{1}$. In addition, the $\mathrm{AD}$ endothelium is less sensitive to $\mathrm{O}_{2}$, which would cause its constriction ${ }^{9,10}$.

\section{Treatment}

The goal is to close the PDA or minimize complications until its spontaneous closure ${ }^{1}$. For diagnostic confirmation, echocardiography is the gold standard, as it can assess the diameter of the $\mathrm{AD}$ and the flow through the shunt ${ }^{11,12}$. The clinical findings of the disease, the patient's weight, and the morphology of the duct are important factors for the choice of treatment ${ }^{8}$.

The initial treatment is usually clinical. Surgery is utilized when the pharmacological approach is contraindicated, as in the case of complications, including necrotizing enterocolitis, intraventricular hemorrhage, and renal failure ${ }^{8,13}$.

Percutaneous access is another option for AD closure ${ }^{1,5,8,14,15}$. However, comparative meta-analyses have shown that reoperations are more common in patients treated with percutaneous closure than with surgical ligation ${ }^{5,16-18}$.

\section{Thoracotomy}

The goal is to directly ligate the $\mathrm{AD}$. The incision is made laterally to the left and the duct is clipped. It is used in patients refractory to pharmacological treatment or contraindicated for clinical treatment ${ }^{7}$.

This safe and reliable approach has similar mortality and complication rates to thoracoscopy ${ }^{3}$. However, there are observational data indicating that open surgery is associated with worsening neurodevelopment of the neonate ${ }^{18}$. In addition, the procedure presents some immediate complications, such as rib fractures, which could be avoided with thoracoscopy $y^{3,14,15}$.

\section{Thoracoscopy}

Thoracoscopy is a minimally invasive method widely used as a treatment for aortic abnormalities, diaphragmatic hernia, and esophageal atresia. This is possible due to the optimization of surgical technologies and newly available equipment ${ }^{1,8}$.

Multiple studies in the literature support the efficacy and safety of thoracoscopy as a form of treatment for PDA ${ }^{19}$. Complication rates range from $0.75-5 \%$ and the surgical success rate from 98.2-99.1\%. Comparative studies between thoracotomy and thoracoscopy showed that there are no differences in safety or efficacy between the procedures 5 . However, there was a decrease in postoperative pain, in the incidence of chest wall deformities, such as scoliosis, and in surgical time and hospital stay after thoracoscopy $y^{3,8}$. 


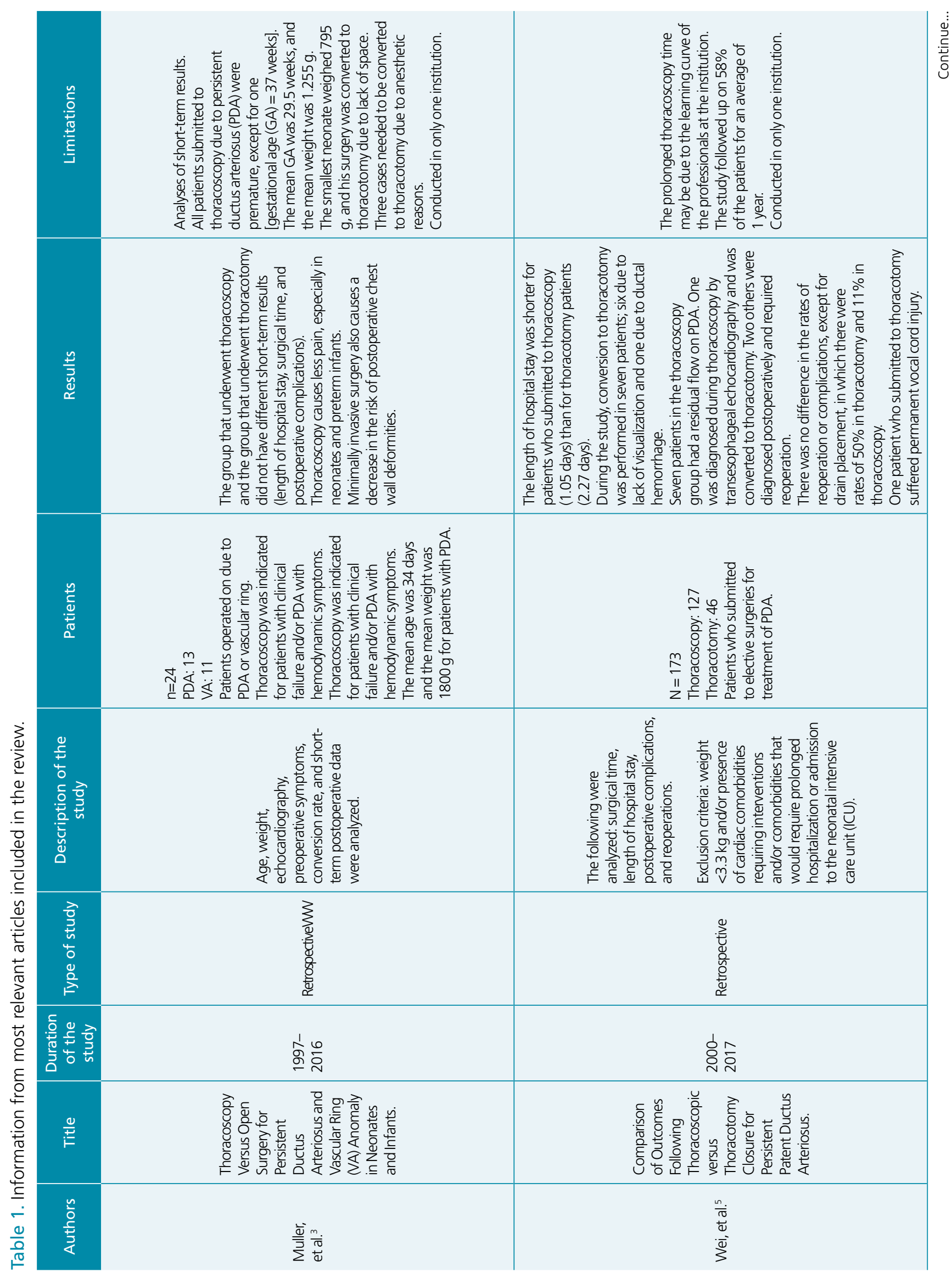




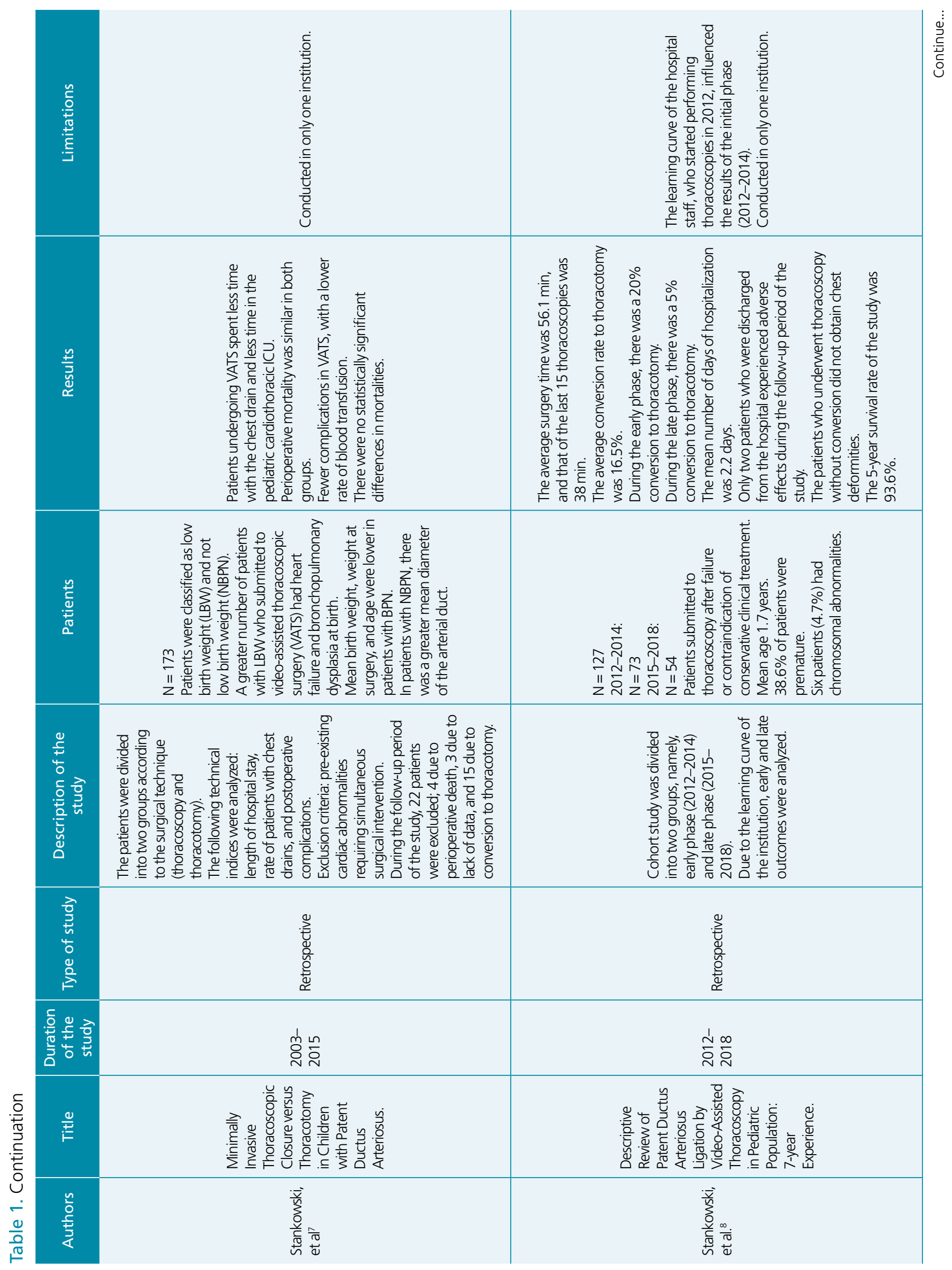




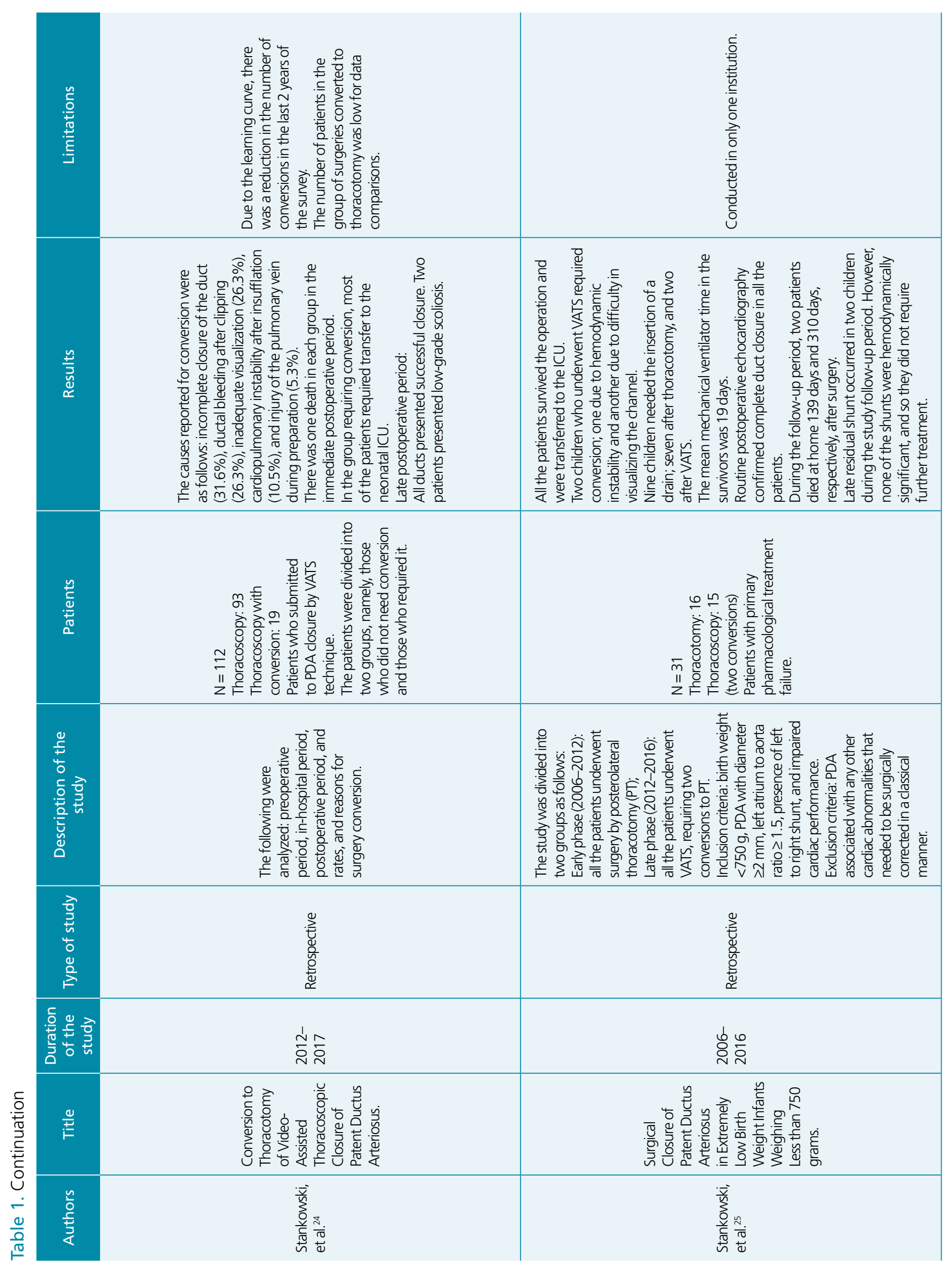


Yet, the greatest limitation of thoracoscopy is the lack of training of professionals. Some studies showed that surgeons must perform at least 50 procedures to feel comfortable, and even more procedures are needed to reduce the surgical time of the thoracoscopic option. Therefore, the learning curve of surgeons should be taken into consideration. The more clinical cases a surgeon has performed, the more it is expected that the surgical time and the length of hospital stay will decrease ${ }^{5,20,21}$.

Some studies have reported that demonstrated shorter hospital stay, while others found no such difference. However, the studies that did not find such a difference were carried out with fewer patients and mainly investigated premature infants. Therefore, there is currently a consensus that thoracoscopy reduces the length of stay in the neonatal intensive care unit (ICU). This may be due to the reduced need for placing drains in patients $s^{5,7,22,23}$.

The technological development of minimally invasive surgical instruments for better adaptation to the bodies of neonates should improve compliance rates with the thoracoscopic method and decrease therapeutic costs ${ }^{5,24,25}$.

Finally, thoracoscopy is more cost-effective than thoracotomy because there is less need for drains and re-intervention and lower complication rates, such as vocal cord injury and pneumothorax ${ }^{5,24}$.

\section{CONCLUSIONS}

Based on the analyzed studies, it is possible to confirm that thoracoscopy and conventional surgery are equally safe and effective, regardless of the child's age. Thoracoscopy is associated with a shorter hospital and ICU stay, is less traumatic and painful, and has a shorter operative time, excellent cost-benefit ratio, good aesthetic results, and low rate of acute complications. Before the end of thoracoscopy, monitoring via transesophageal echocardiography is essential to verify residual flow regardless of the surgeon's experience. Conversion to conventional surgery is rare and does not result in increased complications. It is essential to have a specialized and trained team for the success of this procedure. Finally, more clinical studies comparing these techniques are needed to encourage the medical community to choose thoracoscopy as a surgical treatment for PDA.

\section{AUTHORS" CONTRIBUTIONS}

GCMV: Conceptualization, Data curation, Formal analysis, Investigation, Methodology, Project administration, Visualization, Writing-original draft, Writing - review and editing. MMJ: Data curation, Formal analysis, Investigation, Methodology, Visualization, Writing-original draft, Writing - review and editing. JGMCB: Data curation, Formal analysis, Investigation, Methodology, Visualization, Writingoriginal draft, Writing - review and editing. LABAP: Data curation, Formal analysis, Investigation, Methodology, Visualization, Writing-original draft, Writing - review and editing. ALBG: Data curation, Formal analysis, Investigation, Methodology, Visualization, Writing-original draft, Writing review and editing. ACDA: Conceptualization, Supervision, Validation, Visualization, Writing - review \& editing. AVT: Conceptualization, Supervision, Validation, Visualization, Writing - review \& editing.

\section{REFERENCES}

1. Conrad C, Newberry D. Understanding the pathophysiology, implications, and treatment options of patent ductus arteriosus in the neonatal population. Adv Neonatal Care. 2019;19(3):17987. https://doi.org/10.1097/ANC.0000000000000590

2. Kemmochi M, Senzaki H, Miyaji K, Hashimoto M, Yamaguchi A, Ooka M, et al. Optimal timing of video-assisted thoracoscopic surgery for patent ductus arteriosus in preterm infants born at $\leq 28$ weeks of gestation. Pediatr Int. 2019;61(8):792-6. https://doi.org/10.1111/ped.13909

3. Muller CO, Ali L, Matta R, Montalva L, Michelet D, Soudee S, et al. Thoracoscopy Versus Open Surgery for Persistent Ductus Arteriosus and Vascular Ring Anomaly in Neonates and Infants. J Laparoendosc Adv Surg Tech A. 2018;28(8):1008-11. https:// doi.org/10.1089/lap.2017.0340

4. Burgmeier C, Schier F. Are Cardiac anomalies and persistent fetal circulation a risk factor for cardiovascular events during minimally invasive surgery in neonates? J Laparoendosc Adv Surg Tech A. 2019;29(5):694-7. https://doi.org/10.1089/lap.2018.0579.
5. Wei C, Staffa S, Zurakowski D, Saleeb S, Fynn-Thompson F, Emani SM. Comparison of outcomes following thoracoscopic versus thoracotomy closure for persistent patent ductus arteriosus. Cardiol Young. 2020;30(10):1433-8. https://doi. org/10.1017/S1047951120002206

6. Mattos SS. Fisiologia da Circulação Fetal e Diagnóstico das Alterações Funcionais do Coração do Feto. Arq Bras Cardiol. 1997;69(3):205-7. https://doi.org/10.1590/s0066$782 \times 1997000900013$

7. Stankowski T, Aboul-Hassan SS, Marczak J, Szymanska A, Augustyn C, Cichon R. Minimally invasive thoracoscopic closure versus thoracotomy in children with patent ductus arteriosus. J Surg Res. 2017;208:1-9. https://doi.org/10.1016/j.jss.2016.08.097

8. Stankowski T, Aboul-Hassan SS, SeifiZinab F, Fritzsche D, Misterski M, Sazdovski I, et al. Descriptive review of patent ductus arteriosus ligation by video-assisted thoracoscopy in pediatric population: 7-year experience. J Thorac Dis. 2019;11(6):2555-63. https://doi.org/10.21037/jtd.2019.05.59 
9. Lee JA, Sohn JA, Oh S, Choi BM. Perinatal risk factors of symptomatic preterm patent ductus arteriosus and secondary ligation. Pediatr Neonatol. 2020;61(4):439-46. https://doi. org/10.1016/j.pedneo.2020.03.016

10. Chiruvolu A, Jaleel MA. Pathophysiology of patent ductus arteriosus in premature neonates. Early Hum Dev. 2009;85(3):143-6. https://doi.org/10.1016/j. earlhumdev.2008.12.006

11. Gillam-Krakauer M, Reese J. Diagnosis and Management of Patent Ductus Arteriosus. Neoreviews. 2018;19(7):e394-402. https://doi.org/10.1542/neo.19-7-e394

12. Jain A, Shah PS. Diagnosis, evaluation, and management of patent ductus arteriosus in preterm neonates. JAMA Pediatr. 2015;169(9):863-72. https://doi.org/10.1001/ jamapediatrics.2015.0987

13. Mezu-Ndubuisi OJ, Agarwal G, Raghavan A, Pham JT, Ohler KH, Maheshwari A. Patent ductus arteriosus in premature neonates. Drugs. 2012;72(7):907-16. https://doi.org/10.2165/11632870000000000-00000

14. Backes $\mathrm{CH}$, Rivera BK, Bridge JA, Armstrong AK, Boe BA, Berman DP, et al. Percutaneous Patent Ductus Arteriosus (PDA) closure during infancy: a meta-analysis. Pediatrics. 2017;139(2):e20162927. https://doi.org/10.1542/peds.2016-2927

15. Lam JY, Lopushinsky SR, Ma IWY, Dicke F, Brindle ME. Treatment options for pediatric patent ductus arteriosus: systematic review and meta-analysis. Chest. 2015;148(3):784-93. https://doi. org/10.1378/chest.14-2997

16. Chen $H$, Weng $G$, Chen Z, Wang $H$, Xie Q, Bao J, et al. Comparison of long-term clinical outcomes and costs between video-assisted thoracoscopic surgery and transcatheter amplatzer occlusion of the patent ductus arteriosus. Pediatr Cardiol. 2012;33(2):316-21. https://doi.org/10.1007/s00246011-0130-6

17. Backes $\mathrm{CH}$, Cheatham SL, Deyo GM, Leopold S, Ball MK, Smith CV, et al. Percutaneous Patent Ductus Arteriosus (PDA) closure in very preterm infants: feasibility and complications. J Am Heart Assoc. 2016;5(2):e002923. https://doi.org/10.1161/ JAHA. 115.002923
18. Janz-Robinson EM, Badawi N, Walker K, Bajuk B, Abdel-Latif ME; Neonatal Intensive Care Units Network. Neurodevelopmental outcomes of premature infants treated for patent ductus arteriosus: a population-based cohort study. J Pediatr. 2015;167(5):1025-32. e3. https://doi.org/10.1016/j.jpeds.2015.06.054

19. Chen H, Weng G, Chen Z, Wang H, Xie Q, Bao J, et al. Comparison of posterolateral thoracotomy and video-assisted thoracoscopic clipping for the treatment of patent ductus arteriosus in neonates and infants. Pediatr Cardiol. 2011;32(4):386-90. https://doi. org/10.1007/s00246-010-9863-x

20. McKenna Junior RJ. Complications and learning curves for video-assisted thoracic surgery lobectomy. Thorac Surg Clin. 2008;18(3):275-80. https://doi.org/10.1016/j. thorsurg.2008.04.004

21. Hsieh MJ, Wen CT, Fang HY, Wen YW, Lin CC, Chao YK. Learning curve of image-guided video-assisted thoracoscopic surgery for small pulmonary nodules: a prospective analysis of 30 initial patients. J Thorac Cardiovasc Surg. 2018;155(4):1825-32.e1. https://doi.org/10.1016/j.jtcvs.2017.11.079

22. Vanamo K, Berg E, Kokki H, Tikanoja T. Video-assisted thoracoscopic versus open surgery for persistent ductus arteriosus. J Pediatr Surg. 2006;41(7):1226-9. https://doi. org/10.1016/j.jpedsurg.2006.03.002

23. Esfahanizadeh J, Meybodi NA, Shamloo AS, Shakiba $A H_{\text {, }}$ Hooshiar A, Tashnizi MA, et al. Video-assisted thoracoscopic versus open surgery for persistent ductus arteriosus: report of 10 years' experience. Life Sci J. 2013 [cited on Oct. 12, 2020];10(4):1068-72. Available from: https://www.researchgate. net/publication/258763389

24. Stankowski T, Aboul-Hassan SS, Fritzsche D, Misterski M, Marczak J, Szymańska A, et al. Conversion to thoracotomy of video-assisted thoracoscopic closure of patent ductus arteriosus. Kardiochir Torakochirurgia Pol. 2018;15(2):102-6. https://doi.org/10.5114/kitp.2018.76475

25. Stankowski T, Aboul-Hassan SS, Fritzsche D, Misterski M, Marczak J, Szymańska A, et al. Surgical closure of patent ductus arteriosus in extremely low birth weight infants weighing less than 750 grams. Kardiol Pol. 2018;76(4):750-4. https://doi. org/10.5603/KP.2018.0009 